\title{
Bromoacetaldehyde Diethyl Acetal
}

\section{Joanna Gotkowska}

Bioorganic Chemistry Laboratory, Faculty of Pharmacy, Medical University of Lodz, Muszynskiego 1, 90-151 Lodz, Poland

joanna.gotkowska@umed.lodz.pl

Published online: 12.08 .2015

DOI: 10.1055/s-0034-1381164; Art ID: st-2015-v0522-v

\section{Introduction}

Bromoacetaldehyde diethyl acetal (1) is widely used in chemistry for the synthesis of a variety of antibiotics (including erythromycin and cephalosporins) and other drugs. It is an important and highly reactive bifunctional compound with a good leaving group and a masked aldehyde function. It can be used as a starting material in a variety of reactions to provide $\mathrm{N}$-alkylated compounds, ${ }^{1}$ lactams, ${ }^{2}$ aldehydes,${ }^{3}$ oximes, ${ }^{4}$ azides, ${ }^{5}$ and acyclic di-/polyselenides. ${ }^{3}$

\section{Preparation}

Bromoacetaldehyde diethyl acetal (1) is commercially available and can be prepared by several procedures: from diethylacetal 2 and bromosuccinimide, ${ }^{6}$ from vinyl acetate 3 with bromine in ethanol, ${ }^{7}$ and from 2,4,6-trimethyl-1,3,5trioxane $\mathbf{4}$ with bromine in ethanol. ${ }^{8}$
Joanna Gotkowska was born in Zgierz (Poland) in 1985. She received her M.Sc. in chemistry in 2009 working in the group of Professor Bogusław Kryczka at the University of Lodz (Poland). Currently, she is continuing her research at the Bioorganic Chemistry Laboratory, Faculty of Pharmacy, Medical University of Lodz, working in the group of Assistant Professor Dorota G. Piotrowska. Her research interests focus on synthesis of novel isoxazolidine analogues of homo-N-nucleos(t)ides.
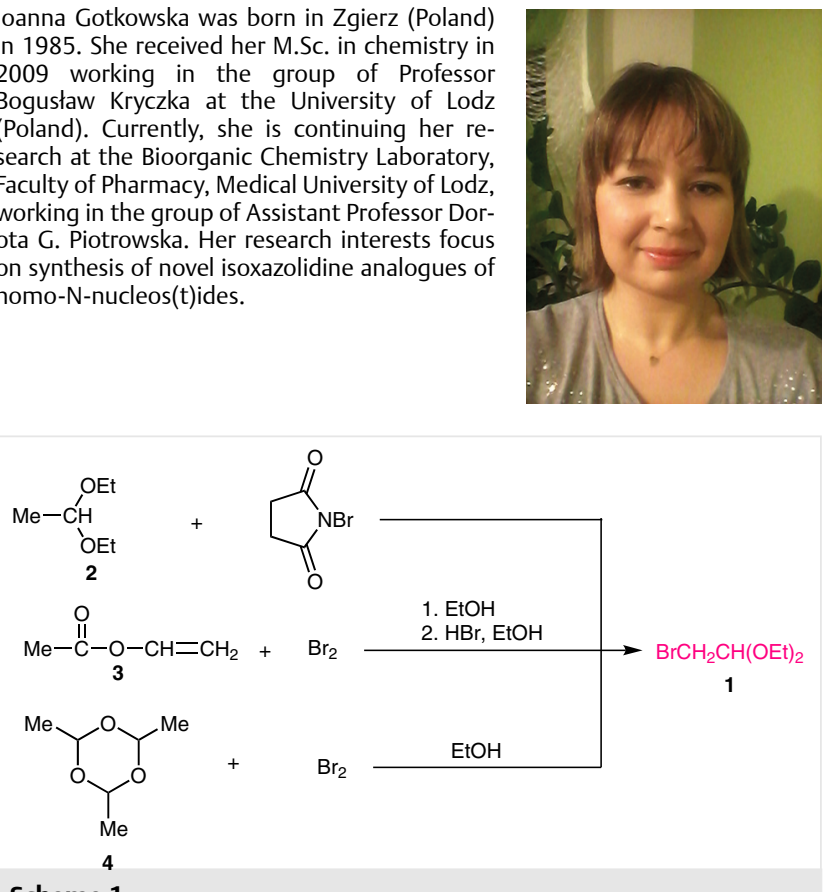

Scheme 1

Table 1 Use of Bromoacetaldehyde Diethyl Acetal

(A) The reaction of bromoacetaldehyde diethyl acetal $\mathbf{1}$ with iso-butyronitrile 5 afforded dihydrofuranone $\mathbf{6}$ in high yield. Reductive amination of $\mathbf{6}$ with $\mathrm{N}$-benzyl- $\mathrm{N}$-(2-phenylethyl)amine led to an ester after EDCI/HOBt-assisted coupling with benzyl alcohol. The oxidative $\mathrm{N}$-debenzylation with CAN allowed to cleanly convert the ester into lactam $7 .^{2}$
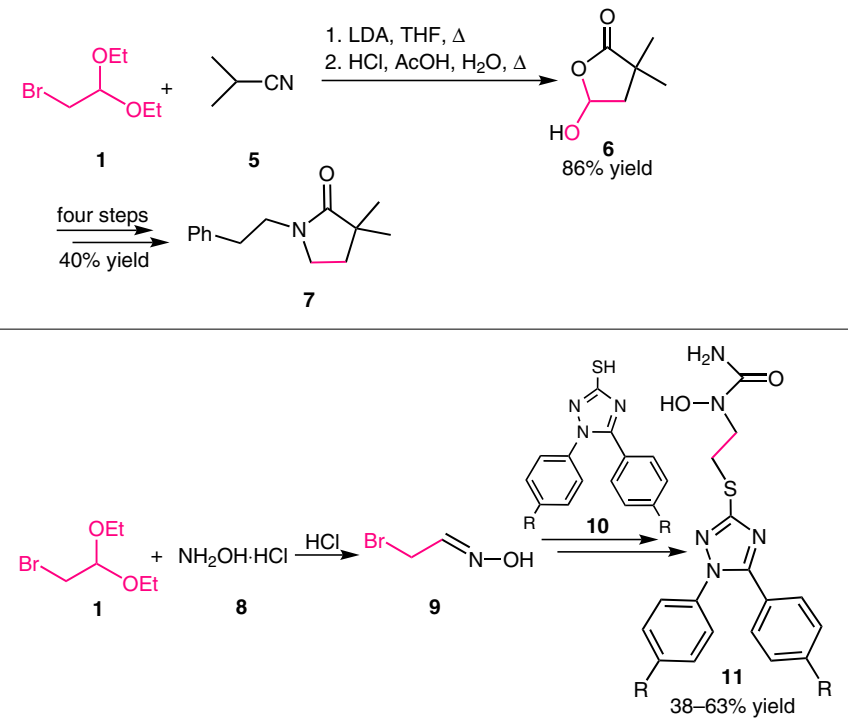

(B) Diaryl-1,2,4-triazoles $\mathbf{1 1}$ bearing an $\mathrm{N}$-hydroxyurea moiety can be obtained in a reaction sequence beginning with the preparation of oxime $\mathbf{9}$ from bromoacetal 1, followed by the bromide displacement in $\mathbf{9}$ after reaction with the thiol 10, and a two-step installation of a carbamoyl fragment. ${ }^{4}$ 
(C) 2-Azido-1,1-diethoxyethane $\mathbf{1 3}$ was prepared from $\mathbf{1}$ and sodium azide 12. The Staudinger-aza-Wittig reaction of $\mathbf{1 3}$ with cyclohexane-1,3-dione $14(\mathrm{R}=\mathrm{H})$ afforded an enamine, which upon treatment with TFA gave 6,7-dihydro- $1 H$-indol-4(5H)-one 15 $(\mathrm{R}=\mathrm{H})$. Application of substituted 1,3-dicarbonyl compounds 14 expanded the scope of this efficient approach to a variety of pyrroles. ${ }^{5}$

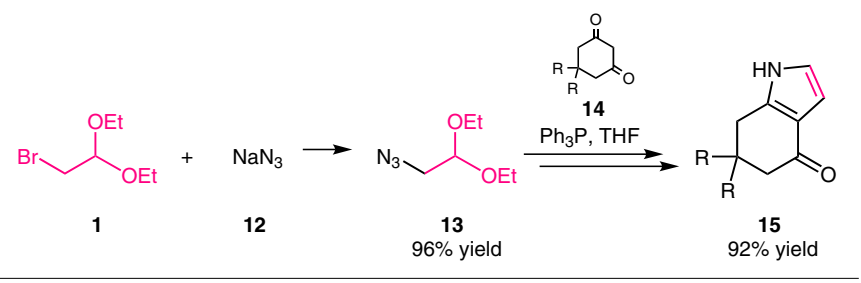

(D) Dicyano acetal 17 was prepared from 1 and malononitrile 16, and was further transformed into a pyrimidine derivative, a precursor to $7 \mathrm{H}$-pyrrolo[2,3-d]pyrimidin-4-amine $18 .{ }^{9}$

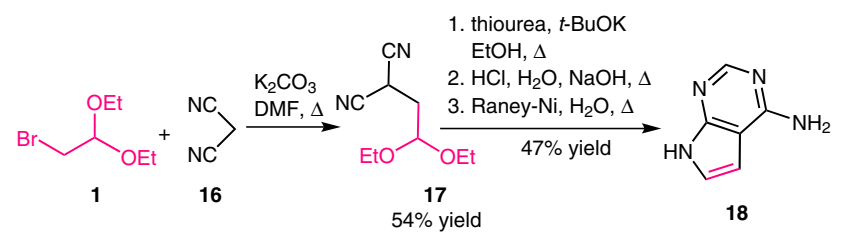

(E) Regioselective alkylation of resacetophenone $\mathbf{1 9}$ with $\mathbf{1}$ afforded compound 20. Under acidic conditions, an intermediate aldehyde was formed from which substituted benzofuran derivative was obtained. Baker-Venkataraman rearrangement followed by acid-catalyzed cyclization led to the formation of furanoflavonoids $\mathbf{2 1}{ }^{10}$

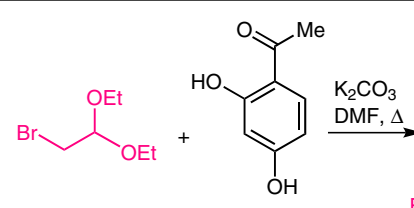

1

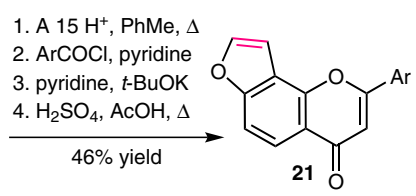

19<smiles>CCOC(COc1ccc(C(C)=O)c(O)c1)OCC</smiles>

20

$90 \%$ yield

(F) The Michaelis-Arbusov reaction of bromoacetal 1 with triethyl phosphite $\mathbf{2 2}$ gave phosphonate $\mathbf{2 3}$, which was transformed into $(E)$ diethyl 2-ethoxyvinylphosphonate and further into a vinylphosphate. The latter compound served as an efficient acceptor in the synthesis of acyclic nucleoside phosphonates $24 .{ }^{11}$

$$
\underset{1}{\stackrel{22}{\longrightarrow} \underset{17 \% \text { yield }}{\longrightarrow}}
$$

(G) Bromoacetal 1 was applied as a starting material in the synthesis of the Se-protected selenide $\mathbf{2 6}$, which after acidic hydrolysis was used in the Ugi four-component reaction using carboxylic acid, isonitrile, and ammonium chloride (as a source of ammonia) to form bisamide $\mathbf{2 7}$ as selenocysteine dipeptides. ${ }^{3}$

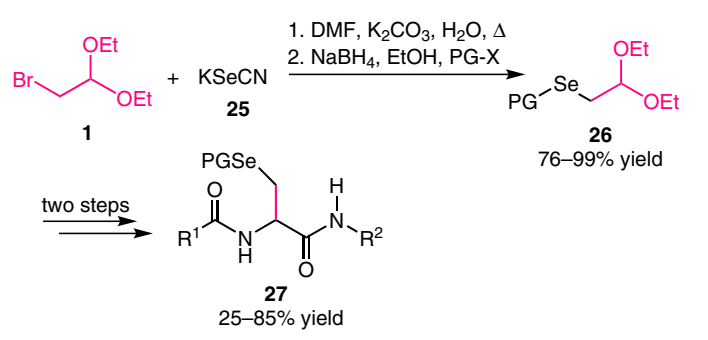

\section{References}

(1) Yu, Q.; Carlsen, P. Molecules 2008, 13, 701.

(2) Davies, S. G.; Mortimer, D. A. B.; Mulvaney, A. W.; Russell, A. J.; Skarphedinsson, H.; Smith, A. D.; Vickers, R. J. Org. Biomol. Chem. 2008, 6, 1625.

(3) Abbas, M.; Wessjohann, L. A. Org. Biomol. Chem. 2012, 10, 9330.

(4) Jiang, B.; Huang, X.; Yao, H.; Jiang, J.; Wu, X.; Jiang, S.; Wang, Q.; Lu, T.; Xu, J. Org. Biomol. Chem. 2014, 12, 2114.

(5) Bellur, E.; Yawer, M. A.; Hussain, I.; Riahi, A.; Fatunsin, O.; Fischer, C.; Langer, P. Synthesis 2009, 2, 227.

(6) Keiko, N. A.; Stepanowa, L. G.; Kleptsova, E. A.; Vdovina, G. P.; Odegova, T. F. Pharm. Chem. J. 2009, 43, 202.
(7) McElvain, S. M.; Kundiger, D. Org. Synth. 1943, 23, 8.

(8) Baganz, H.; Dossow, K. H.; Hohmann, W. Chem. Ber. 1953, 86, 148.

(9) Jung, M.-H.; Kim, H.; Choi, W.-K.; El-Gamal, M. I.; Park, J.-H.; Ho Yoo, K.; Bo Sim, T.; Ha Lee, S.; Baek, D.; Hah, J.-M.; Cho, J.-H.; Oh, Ch.-H. Bioorg. Med. Chem. Lett. 2009, 19, 6538.

(10) Dixit, M.; Tripathi, B. K.; Tamrakar, A. K.; Srivastava, A. K.; Kumar, B.; Goel, A. Bioorg. Med. Chem. 2007, 15, 727.

(11) Dayde, B.; Benzaria, S.; Pierra, C.; Gosselin, G.; Surleraux, D.; Volle, J. N.; Pirat, J. L.; Virieux, D. Org. Biomol. Chem. 2012, 10, 3448. 